\title{
Anti Hypertensive Activity of the Ethanolic Extract of Lantana camara leaves on high salt loaded wistar albino rats
}

\author{
Vijay Kumar Matta, Praveen Kumar Pasala*, Silvia Netala, Satish Pandrinki and Prasad Konduri \\ Department of Pharmacology, Shri Vishnu College of Pharmacy, Bhimavaram, Andhra Pradesh, India.
}

\begin{abstract}
Background: Hypertension is the most common and major cardiovascular disease. There is an urgent need for treament of hypertension by exploration of several medicinal plants having potent anti hypertensive activity as the modern medicines are having many side effects. Objective: The study focus on scientific evaluation of antihypertensive activity of ethanolic extract of Lantana camara leaves (EELC) in different experimental models.

Material \& methods: Antihypertensive activity was conducted on wister albino rats by determining serum glutamic oxaloacetic transaminase (SGOT), serum glutamic pyruvic transaminase (SGPT), creatinine and Sodium levels by using Semi Autoanalyser and Flame photometer; chick mean arterial blood pressure by using condon's mercury manometer and isolated frog heart for recording cardic responses using student kymograph. Results: EELC produced negative inotropic and negative chronotropic effect, antagonised by atropine on isolated frog heart. EELC shows dose dependent $(p<0.05)$ decreased mean arterial blood pres $\neg$ sure (MABP) in anaesthetic chick. Salt treated rats displayed significant $(p<0.05)$ increase in blood level of SGOT, SGPT, Creatinine and sodium, de $\neg$ crease in pottassim levels in comparision with normal rats. Treatment with EELC (200 and 400 $\mathrm{mg} / \mathrm{kg}$ ) significantly balanced the ionic levels such as lower the sodium and elevate the potassium levels. Creatinine levels were signifi-cantly $(p<0.05)$ reduced by the treatment with EELC. There are no significant changes occurred in serum SGOT and SGPT upon EELC administration. The present study suggests that treatment of salt hypertensive rats with EELC protects against renal injuries. Conclusion: It was concluded that ethanolic extract of Lantana camara leaves reduces work load of heart, maintain inotonic levels by negative chronotropic effect, relaxes the smooth muscles in chick and salt hypertensive rats against renal and vascular injuries is proved.
\end{abstract}

Key words: EELC (Ethanolic extract of Lantana camara leaves), Wistar albino rats, Hypertension, Mean arterial blood pressure (MABP) and Normotensive rats (NTR)

\section{SUMMARY}

- Lantana camara is belongs to family verbenaceae, biologically Lantana camara linn.

- EELC exhibited biphasic response, initially negative ionotropic and negative chronotropic effect followed by sharp positive ionotropic effect, the early response, such as negative inotropic and chronotropic effect.

- EELC exhibited a dose dependent decrease in the mean arterial blood pressure (MABP) of anaesthetized chick.

- EELC $400 \mathrm{mg} / \mathrm{kg}$ significantly maintain ionic level ( increased the potassium levels and decrease Sodium levels) on salt induced hypertensive rats.

- In the salt hypertensive rats, the kidney exhibited pathological abnormalities such as cortical degeneration, tubular degeneration, hydrophilic swelling and necrotic changes were observed. In the control, standard and plant extract treated rats, the kidney exhibited a normal architecture.

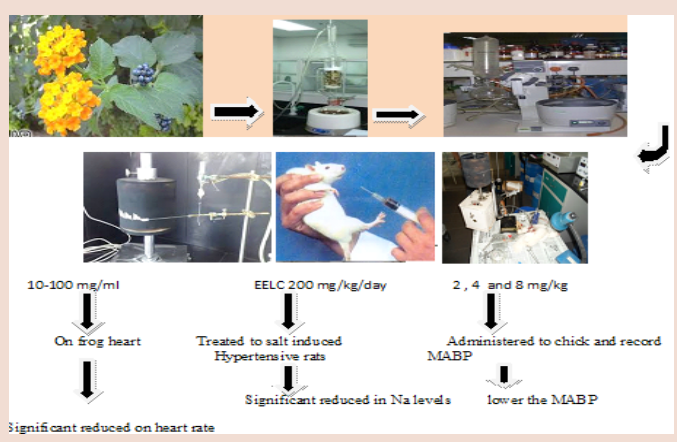

\section{PICTORIAL ABSTRACT}

Abbreviations used: EELC: Ethanolic extract of Lantana camara leaves, MABP: Mean arterial blood pressure,Na: Sodium, mg: milligrams, ml: milliliters, kg: kilogram.

\section{Correspondence:}

Prof. Praveen Kumar Pasala, Associate professor, Department of Pharmacology, Shri Vishnu College of Pharmacy, Bhimavaram 534202, West Godavari, Andhra Pradesh, India.

Email: praveenpharmaco@gmail.com

DOI : 10.5530/pj.2015.5.7

\section{INTRODUCTION}

Hypertension is most common cardiovascular disease and is a major public health issue. Recent studies have reported an increasing trend in the prevalence of hypertension in Indian subcontinent. This increase was found to be about $30 \%$ in urban population and $10 \%$ in rural habitants in last three decades. ${ }^{1}$ Lantana camara is belongs to family verbenaceae, biologically Lantana camara linn. The Lantana camara was screened for anticancer activity, Oleanonic acid exhibited promising cytotoxicity against A375 cells. ${ }^{2-3}$ Antimicrobial activity on E. Coli, S. aureus, ${ }^{4-5}$ Antifungal activity, ${ }^{6}$ Hypoglycemic activity, ${ }^{7}$ Anti-inflammatory activity, ${ }^{8}$ Antimotility activity, ${ }^{9}$ Wound healing effect. ${ }^{10-11}$ Even though they are several modern medicines for treatment of hypertensive but the same times having equal side effects. Hence there is an urgent need for treament of hypertensive activity by exploration of they are several medicinal plants having potent anti hypertensive activity. ${ }^{12}$ The present study was done to evaluate the anti hypertensive activity of EELC using various animal models.

\section{EXPERIMENTAL DESIGN}

\section{Materials and methods}

Collection of plant and preparation of extract

Lantana camara was collected from shri Vishnu botanical garden, authenticated by the botanist. Mrs. P. Prasanna Kumari. Head of the Department of Botany, D.N.R (A) College, Bhimavaram, Andhra Pradesh, India. Powdered plant material of leaves of Lantana camara were first defatted using petroleum ether $\left(60-80^{\circ} \mathrm{C}\right)$. Preparation of etanolic extract by $30 \mathrm{~g}$ of powdered plant material was packed in soxhlet apparatus and subjected to continuous hot percolation for 8 hours. The percentage yield of the ethanolic extract was $10.80 \% \mathrm{w} / \mathrm{w}$.

\section{Experimental design for study the effect EELC on Isolated Frog Heart}

Frog was sacrificed with a head-blow using a steel rod and pith it. The skin and abdomen were cut and opened. Cut the pectoral girdle using a 
bone cutter and remove pericardium. Syme's cannula, connected to the reservoir of frog Ringers solution and immediately into the Sinus venous of the heart through posterior vena cava. Cut the connecting blood vessels and take out the heart from the animal and mounted on a stand. Covered the heart with a thin layer of cotton wool to prevent drying. Wet the heart frequently with the physiological solution to prevent drying, connect the heart to the Starling lever, which in turn is connected to the smoked drum for recording the responses of the heart. The level of frog Ringers solution in the Syme's cannula was maintained by a fixing a glass tube into the cork fixing to the reservoir (Marriotte's bottle) tightly. The heart was allowed to stabilize and when the heart rate and cardiac output were taken, the recordings were made on slow rotating drum kymograph paper. The extract was dissolved in Frog ringer's solution to obtain appropriate concentrations of $1,2,4,8$ and $10 \mathrm{mg} / \mathrm{ml}$ and studied heart rate (HR), Cardiac output (CO) and force of contraction presence of Atropine. ${ }^{13}$

\section{Experimental design for the hypotensive activity of EELC on anaesthetized chick model}

Chick of either sex weighing between $(0.5-1.5 \mathrm{~kg})$ were anaesthetize with Phenobarbital sodium (60-90 mg/kg) given intramuscularly. Rat and chick are the only species of experimental animals which require such a heavy dose of Phenobarbital sodium. When corneal reflexes are lost, shift the animal to an operation table. Secure the neck and the limbs properly to the nails using a twine. Then animal may be kept warm with heat from an electric bulb, expose the trachea with a vertical cut on the neck and retract the muscles around the trachea with vertical teasing of the muscles using the iris-dissecting forceps. Cannulate the trachea with a polythene cannula to put the chick on artificial ventilation if required. ${ }^{13}$ The tracheal secretions which normally cause respiratory embarrassment, particularly in older animals, cleared by sucking out using a $2 \mathrm{ml}$ syringe with a hypodermic needle whose level is cut and a polythene cannula sleeved over it. Cannulate the right external ischiadic vein with a polythene cannula, for the administration of the agonists and plant extract. Carefully free the ischiadic artery (IA), located much deeper below to the side position (above the femoral bone), from the adhering tissues carefully free the associated nerve and a fine blood vessel running parrel to IA. Pass two threads bellows the IA and make two loose loops around it. Tie off the distal loop at a site as close to the head as possible. Keeping the retracted forceps below the blood vessels often help in tying the distal loop sufficiently distal to the proximal loop. Apply a bulldog clip very close to the proximal clip. Introduce the arterial cannula carefully in IA. Heparin of $500 \mathrm{IU}$ after dilution was administrated into the arterial cannula. Tie the proximal loop over the arterial cannula, which is connected to a Condon's mercury float manometer in which a positive pressure (normally $120 \mathrm{mmHg}$ ) is maintained. Release the clamp on the link tube slowly. Record the Mean arterial blood pressure (MABP) on a slow moving smoked paper, administration of the agonist the various concentration of EELC $(2,4$ and $8 \mathrm{mg}) 20$ minutes after the cannulating of the IA. If there any blood loss during the dissection, warm the normal saline or dextrin solution can be administered slowly through the venous cannula.

\section{Experimental design for the antihypertensive activity of EELC on salt induced hypertensive rats}

Three months old male Wristar albino rats, weighting between 180 and $200 \mathrm{~g}$ were used. Animals were acclimate in the Animal House (Regd. No:439//PO/01/a/CPCSEA) at Shri Vishnu College of Pharmacy, Bhimavaram, and Andhra Pradesh, INDIA). Rats were fed with standard diet and water ad-libitum. Normotensive rats were randomly divided into five groups, and each group group consists six animals. ${ }^{14-15}$

- Group I, Normal control, received distilled water served as nor-
Table 1: Preliminary Qualitative Phytochemical study of the Lantana camara plant extracts

\begin{tabular}{ccccc}
\hline \multicolumn{5}{c}{ Various extracts of Lantana camara } \\
$\begin{array}{c}\text { Type of extract } \rightarrow \\
\text { Test for }\end{array}$ & Pet ether & Chloroform & Ethanol & Aqueous \\
\hline Carbohydrate & - & + & + & + \\
Alkaloids & + & - & + & - \\
Glycoside & - & + & + & - \\
Polypeptides & + & - & + & - \\
Saponins & - & + & + & + \\
Tannins & + & + & + & - \\
Fats and Oils & - & - & - & - \\
Flavonoids & - & + & + & - \\
Terpenoids & + & + & - & - \\
Steroids & + & + & + & + \\
\hline
\end{tabular}

Note: pet. Ether - petroleum ether, + - Present, - - Absent.

motensive rats.

- Group-II, Disease control, received $18 \% \mathrm{NaCl}$ (10 ml $/ \mathrm{kg} /$ day), served as salt hypertensive rats (SHR).

- Group III, Received $18 \% \mathrm{NaCl}(10 \mathrm{ml} / \mathrm{kg} /$ day $)+$ Spironolactone $(0.71 \mathrm{mg} / \mathrm{kg})$.

- Group IV, Received 18\% NaCl (10 ml/kg/day) + EELC 200 (mg/ $\mathrm{kg}$ /day).

- Group V, Received 18\% NaCl (10 ml/kg/day) + EELC 400 (mg/ $\mathrm{kg} /$ day).

This experimental protocol follows up to 28 days. On $0,7,14,21$ and 28 days to estimate Creatinine, Serum glutamic oxaloacetic transaminase (SGOT) Serum glutamic pyruvic transaminase. (SGPT), Sodium and Potassium levels. At the end of this experimental period, all the animals were sacrificed and isolate the kidneys and trimmed of any fatty tissue and stored in $10 \%$ neutral phosphate buffered formalin solution for histological studies. ${ }^{16}$

\section{Histological studies of kidney in different groups of rats}

Histopathology examination of renal slices from different groups of rats were examined.

\section{RESULT}

\section{Preliminary Qualitative Phytochemical studies of the plant extracts}

Preliminary phytochemical investigation reports the presence of various phytoconstiuents and are summarized in Table 1. Major constituents are Glycosides, Saponins, Tannins, Flavonoids, Terpenoids and Steroids.

\section{Effect of EELC on isolated frog heart}

Table 2, Figure 1a,1b, $2 \mathrm{a}$ and $2 \mathrm{~b}$ shown that the EELC extract produced dose dependent negative inotropic and negative chronotropic effect on isolated frogs heart. The observed responses antagonized by atropine.

Effect of EELC on mean arterial blood pressure using anaesthetized chick

Table 3, Figure 3a, 3b Shown that the extract produced significantly $(\mathrm{P}<$ 0.05 ) reduced mean arterial blood pressure on anaesthetized chick in a dose dependent manner. 
Table 2: Effect of EELC on heart rate presence of Atropine (150 $\mu \mathrm{g} / \mathrm{ml})$ using isolated frogs heart

\begin{tabular}{ccccc}
\hline & \multicolumn{2}{c}{ Heart rate $($ beats $/ \mathrm{min})$} & \multicolumn{2}{c}{ Force of contraction } \\
\cline { 2 - 5 } EELC $(\mathrm{mg})$ & EELC & $\begin{array}{c}\text { EELC }+ \text { ATP } \\
(150 \mu \mathrm{g})\end{array}$ & EELC & $\begin{array}{c}\text { EELC + ATP } \\
(150 \mu \mathrm{g})\end{array}$ \\
\hline Normal & 85 & 100 & 7.5 & 7.5 \\
$\mathbf{1}$ & 69 & 80 & 7 & 7.6 \\
$\mathbf{2}$ & 68 & 76 & 6.5 & 7.9 \\
$\mathbf{4}$ & 63 & 73 & 6.1 & 8.3 \\
$\mathbf{8}$ & 60 & 68 & 5.1 & 8.9 \\
$\mathbf{1 0}$ & 56 & 69 & 1.3 & 8.5 \\
\hline
\end{tabular}

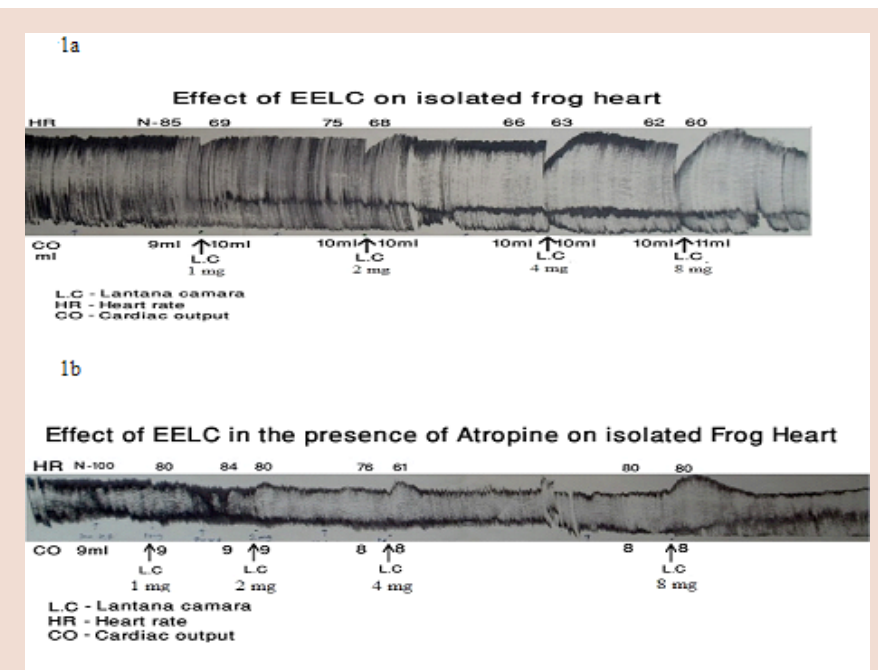

Figure 1: Effect of EELC on isolated frog heart

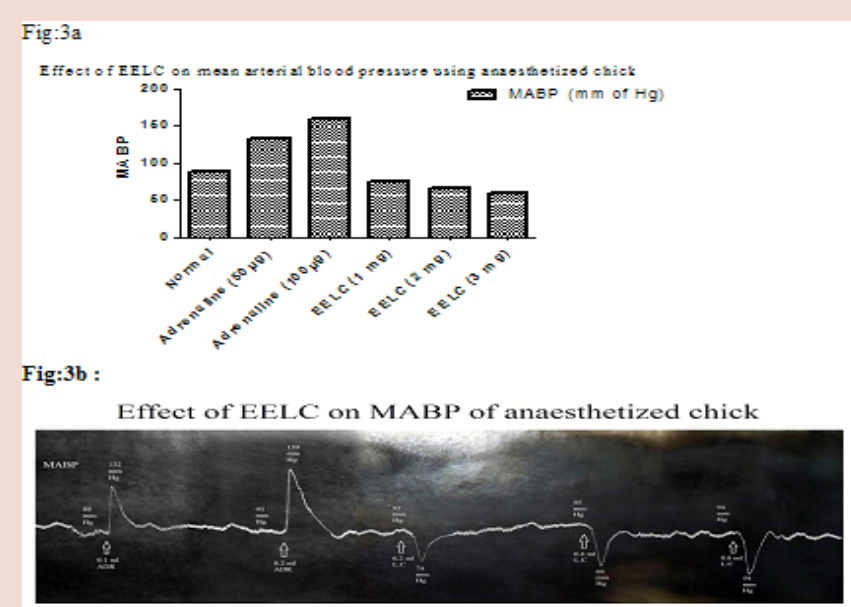

shar.

Figure 3: Effect of EELC on mean arterial blood presure on anaesthesised chick

Effects of EELC on SGOT and SGPT on salt induced hypertensive rats Table 4, Figure 4a, $4 \mathrm{~b}$ Salt loaded rats showed a significant ${ }^{*}(\mathrm{P}<0.05)$ increase in blood levels of SGOT and SGPT, as compared to NTR. EELC (200 and $400 \mathrm{mg} / \mathrm{kg} /$ day) less significantly to reduced the rise of concentrations of SGOT and SGPT.
Table 3: Effect of EELC on mean arterial blood pressure using anaesthetized chick

\begin{tabular}{ccc}
\hline $\mathbf{Z}$ & Drug (Con.) & MABP $(\mathrm{mm}$ of $\mathrm{Hg})$ \\
\hline $\mathbf{1}$ & Normal & 88 \\
$\mathbf{2}$ & Adrenaline $(50 \mu \mathrm{g})$ & 132 \\
$\mathbf{3}$ & Adrenaline $(100 \mu \mathrm{g})$ & 159 \\
$\mathbf{4}$ & EELC $(1 \mathrm{mg})$ & 74 \\
$\mathbf{5}$ & EELC $(2 \mathrm{mg})$ & 66 \\
$\mathbf{6}$ & EELC $(3 \mathrm{mg})$ & 59 \\
\hline
\end{tabular}

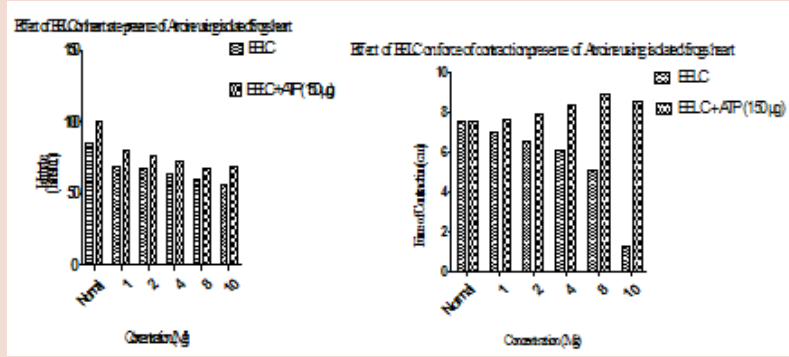

Figure 2: Effects of EELC on force of contraction in the presence of Atropine on isolated frog heart.

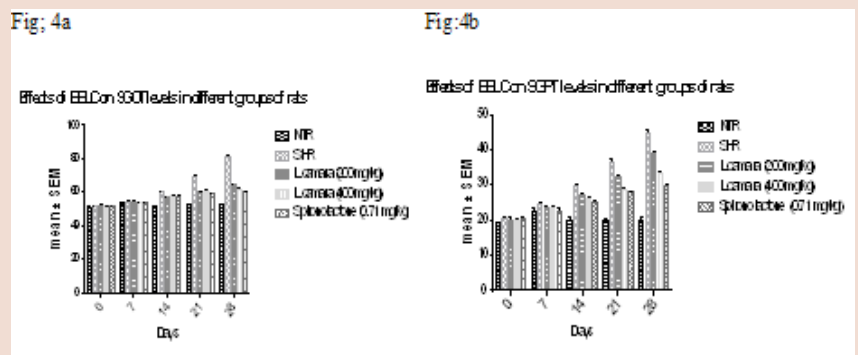

Figure 4: Effect of EELC on SGOT and SGPT in wistar albino rats

Effects of EELC on Creatinine levels on salt induced hypertensive rats Table 5, Figure 5a shows Salt loaded rats displayed a significant ${ }^{* *}(\mathrm{P}<$ $0.05)$ increase in blood levels of Creatinine, as compared to NTR. EELC (200 and $400 \mathrm{mg} / \mathrm{kg} /$ day) less significant reduced the rise of concentrations of creatinine. Similar results were observed in animals treated with 
Table 4: Effects of EELC on SGOT and SGPT on salt induced hypertensive rats

\begin{tabular}{cccccc}
\hline Days & Group-I & Group-II & Group-III & Group-IV & Group-V \\
\hline \multicolumn{5}{l}{ Serum glutamic oxaloacetic transaminase } & (SGOT) U/L \\
0 & $51.00 \pm 0.44$ & $51.20 \pm 0.58$ & $52.00 \pm 0.70$ & $51.20 \pm 0.58$ & $51.60 \pm 0.50$ \\
7 & $53.80 \pm 0.37$ & $53.20 \pm 0.37$ & $53.80 \pm 0.66$ & $54.40 \pm 0.50$ & $53.80 \pm 0.37$ \\
14 & $51.60 \pm 0.50$ & $60.40 \pm 0.50$ & $56.60 \pm 0.50$ & $58.20 \pm 0.37$ & $57.60 \pm 0.50$ \\
21 & $52.20 \pm 0.58$ & $68.60 \pm 1.02$ & $60.40 \pm 0.50$ & $60.60 \pm 0.74$ & $58.80 \pm 0.37$ \\
28 & $52.20 \pm 0.66$ & $81.40 \pm 1.02^{* *}$ & $64.40 \pm 0.50$ & $61.80 \pm 0.58$ & $60.00 \pm 0.31^{* *}$ \\
Serum glutamic pyruvic transaminase (SGPT) U/L & & \\
0 & $19.00 \pm 0.44$ & $20.40 \pm 0.50$ & $20.00 \pm 0.70$ & $20.00 \pm 0.54$ & $20.40 \pm 0.50$ \\
7 & $22.40 \pm 0.92$ & $24.60 \pm 0.50$ & $23.40 \pm 0.50$ & $23.60 \pm 0.50$ & $22.60 \pm 0.60$ \\
14 & $20.00 \pm 0.70$ & $29.60 \pm 0.50$ & $27.20 \pm 0.37$ & $26.00 \pm 0.70$ & $25.00 \pm 0.31$ \\
21 & $19.60 \pm 0.50$ & $36.40 \pm 0.92$ & $32.20 \pm 0.37$ & $28.40 \pm 0.50$ & $27.80 \pm 0.37$ \\
28 & $20.00 \pm 0.70$ & $44.40 \pm 1.12^{* *}$ & $39.20 \pm 0.37$ & $33.00 \pm 0.54$ & $29.80 \pm 0.58^{* *}$ \\
\hline
\end{tabular}

Values are expressed in MEAN \pm S.E.M of five animals. One way analysis of variance followed by Dunnetts multiple comparisions test ; ${ }^{* *}(\mathrm{P}<0.05)$ significance between salt treated rats vs EELC (400 mg/kg).

Table 5: Effects of EELC on Creatinine levels on salt induced hypertensive rats

\begin{tabular}{cccccc}
\hline \multicolumn{1}{c}{ Days } & Group-I & Group-II & Group-III & Group-IV & Group-V \\
\hline \multicolumn{1}{c}{ Creatinine $\mathbf{m g} / \mathbf{d l}$ l } & & & & & \\
0 & $0.26 \pm 0.04$ & $0.30 \pm 0.04$ & $0.32 \pm 0.03$ & $0.32 \pm 0.03$ & $0.28 \pm 0.03$ \\
7 & $0.28 \pm 0.03$ & $0.72 \pm 0.03$ & $0.54 \pm 0.050$ & $0.52 \pm 0.03$ & $0.48 \pm 0.03$ \\
14 & $0.32 \pm 0.03$ & $1.14 \pm 0.05$ & $0.82 \pm 0.03$ & $0.86 \pm 0.04$ & $0.58 \pm 0.03$ \\
21 & $0.34 \pm 0.04$ & $1.54 \pm 0.05$ & $1.08 \pm 0.03$ & $0.96 \pm 0.02$ & $0.70 \pm 0.04$ \\
28 & $0.28 \pm 0.03$ & $2.20 \pm 0.07^{* *}$ & $1.44 \pm 0.02$ & $1.18 \pm 0.03$ & $0.98 \pm 0.03^{* *}$ \\
\hline
\end{tabular}

Values are expressed in MEAN \pm S.E.M of five animals. one way analysis of variance followed by Dunnetts multiple comparisions test ; * $(p<0.05)$ Significantly between salt treated rats and EELC (400 mg/kg).

\section{Fig:5a}

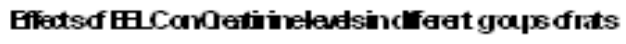
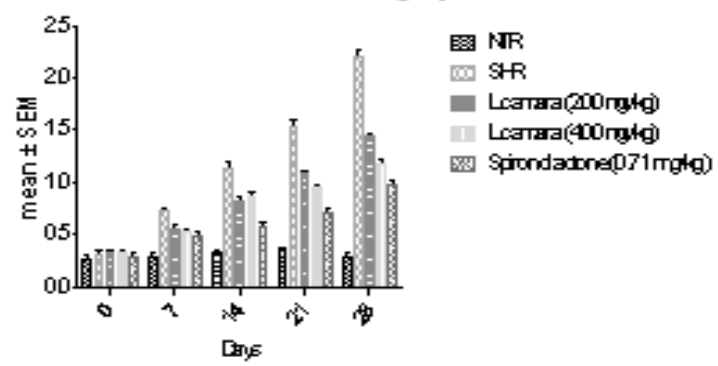

Figure 5: Effect of EELC on Creatinine in wistar albino rats

and Spironolactone $(0.71 \mathrm{mg} / \mathrm{kg} /$ day $)$.

Effects of EELC on Serum Sodium levels in different groups of rats Salt loaded rats displayed a significant ${ }^{* *}(\mathrm{P}<0.05)$ increase in serum levels of Sodium, as compared to NTR. EELC (200 and $400 \mathrm{mg} / \mathrm{kg} /$ day) significantly reduced the rise of concentrations of serum Sodium levels. As Similar to Spironolactone $(0.71 \mathrm{mg} / \mathrm{kg} /$ day $)$. The results were sum-

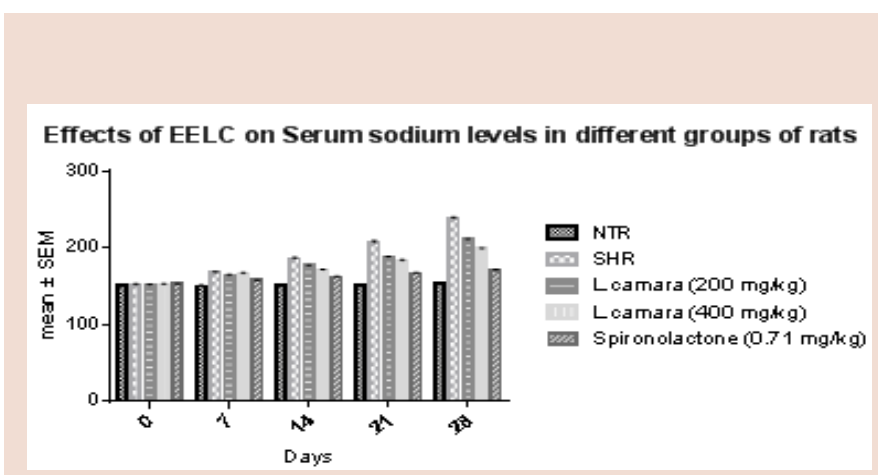

Figure 6: Effect of EELC on Serum Sodium levels in wistar albino rats

marized in Table 6 and depicted in Figure 6.

Effects of EELC on Serum Potassium levels in diiferent groups of rats Salt loaded rats displayed a significant ${ }^{* *}(\mathrm{P}<0.05)$ decrease in serum levels of Potassium, as compared to NTR. EELC (400 mg/kg/day) significantly increased the concentrations of serum Potassium. The results were summarized in Table 7 and depicted in Figure 7. 
Table 6: Effects of EELC on Serum Sodium levels in different groups of rats

\begin{tabular}{cccccc}
\hline Days & Group-I & Group-II & Group-III & Group-IV & Group-V \\
\hline \multicolumn{2}{c}{ Sodium $\mathbf{m E q} / \mathbf{L}$} & & & & \\
0 & $151.46 \pm 0.96$ & $152.12 \pm 0.94$ & $151.80 \pm 1.01$ & $152.48 \pm 1.19$ & $152.80 \pm 0.89$ \\
7 & $150.10 \pm 1.1$ & $168.06 \pm 1.10$ & $164.08 \pm 1.39$ & $166.72 \pm 1.42$ & $157.72 \pm 0.67$ \\
14 & $151.78 \pm 1.10$ & $186.12 \pm 1.59$ & $176.84 \pm 0.83$ & $171.40 \pm 0.81$ & $162.22 \pm 0.83$ \\
21 & $151.10 \pm 0.65$ & $207.28 \pm 2.34$ & $188.28 \pm 0.74$ & $183.28 \pm 1.54$ & $167.08 \pm 0.92$ \\
28 & $153.42 \pm 1.59$ & $238.88 \pm 1.41^{* *}$ & $211.20 \pm 1.02$ & $199.12 \pm 0.98$ & $171.66 \pm 0.53^{* *}$
\end{tabular}

Values are expressed in MEAN \pm S.E.M of five animals. One way analysis of variance followed by Dunnett's multiple comparisions test ; ${ }^{* *}(\mathrm{p}<0.05)$ significance between salt treated rats vs EELC (400 mg/kg).

Table 7: Effects of EELC on Serum Potassium levels in diiferent groups of rats

\begin{tabular}{cccccc}
\hline Days & Group-I & Group-II & Group-III & Group-IV & Group-V \\
\hline \multicolumn{2}{c}{ Potassium mEq/L } & & & & \\
0 & $6.18 \pm 0.22$ & $5.92 \pm 0.08$ & $5.96 \pm 0.16$ & $5.88 \pm 0.08$ & $6.10 \pm 0.08$ \\
7 & $6.22 \pm 0.10$ & $5.98 \pm 0.06$ & $5.62 \pm 0.12$ & $5.94 \pm 0.05$ & $5.74 \pm 0.08$ \\
14 & $6.20 \pm 0.07$ & $5.86 \pm 0.08$ & $5.54 \pm 0.16$ & $5.96 \pm 0.17$ & $5.62 \pm 0.13$ \\
21 & $6.14 \pm 0.14$ & $5.10 \pm 0.08$ & $5.58 \pm 0.18$ & $6.28 \pm 0.16$ & $6.24 \pm 0.15$ \\
28 & $6.28 \pm 0.29$ & $4.54 \pm 0.09^{* *}$ & $5.52 \pm 0.25$ & $6.56 \pm 0.18$ & $6.20 \pm 0.07^{* *}$ \\
\hline
\end{tabular}

Values are expressed in MEAN \pm S.E.M of five animals. one way analysis of variance followed by Dunnetts' multiple comparisions test ; ${ }^{* *}(\mathrm{p}<0.05)$ significance between salt treated rats vs EELC (400 mg/kg).

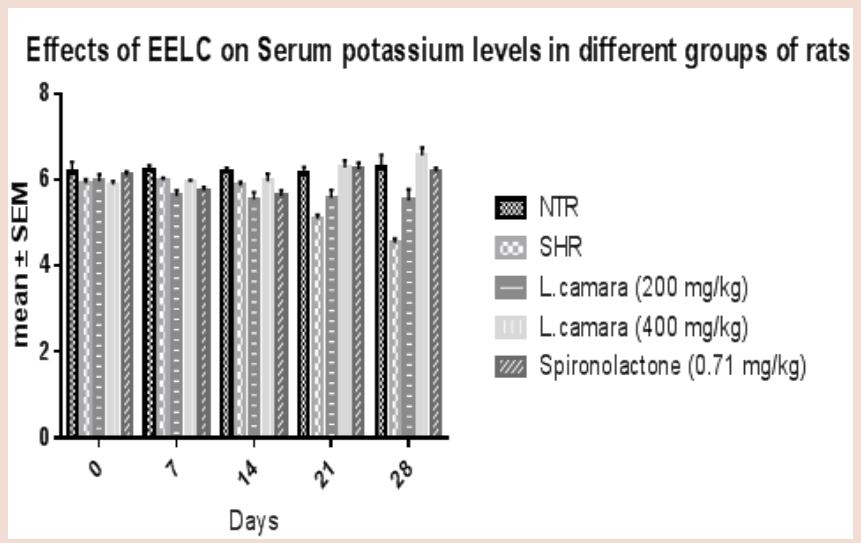

Figure 7: Effect of EELC on Serum Potassium levels in wistar albino rats

Histological studies of different groups of rats kidney

Histopathology examination of renal slices from different groups of rats were examined. Less cortical tubular degeneration observed with treatment of EELC (400 mg/kg). In the salt hypertensive rats, the kidney exhibited pathological abnormalities such as cortical degeneration, tubular degeneration, hydrophilic swelling and necrotic changes were observed. (Figure 8).

\section{DISCUSSION}

EELC exhibited biphasic response, initially negative ionotropic and negative chronotropic effect followed by sharp positive ionotropic effect, the early response, such as negative inotropic and chronotropic effect are antagonized by atropine. Hence these response are mediating through muscaranic receptors. Few reported are suggested the cholinomimetic drugs are reduces workload of heart, hence these agents are benefit in the treat-

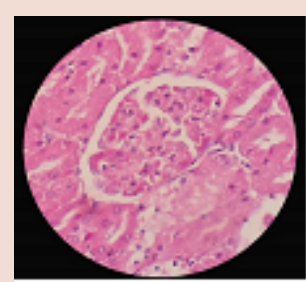

Control (40x)

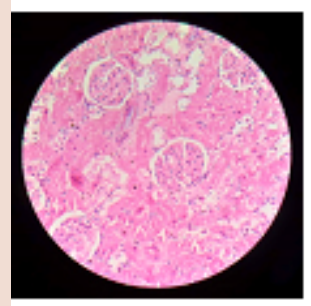

EELC $200 \mathrm{mg} / \mathrm{kg}(40 \mathrm{x})$

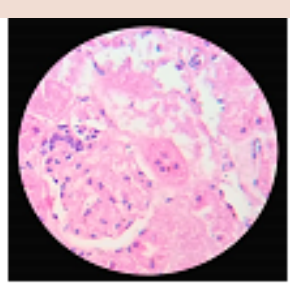

SHR (40x)

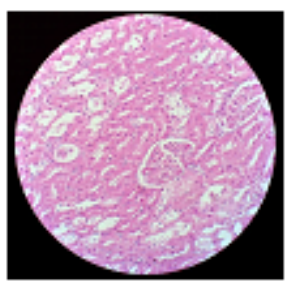

$\mathrm{EELC} 400 \mathrm{mg} / \mathrm{kg}(40 \mathrm{x})$

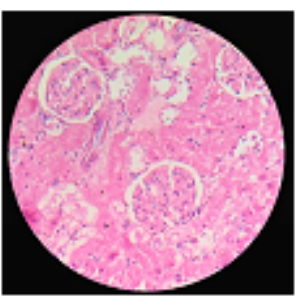

Spironolactone $0.71 \mathrm{mg} / \mathrm{kg}(40 \mathrm{x})$

Figure 8: Histopathological changes of kidneys in various groups of salt hypertensive rats 
ment of cardio vascular complication. such as hypertension. ${ }^{17}$ This result might represent evidance for the antihypertensive activity of EELC (Table 2, Figure 1a, 1b, 2a \& 2b) EELC exhibited a dose dependent decrease in the mean arterial blood pressure (MABP) of anaesthetized chick (Table 3 , Figure $3 \mathrm{a} \& 3 \mathrm{~b}$ ). It is interesting to note that have similarly reported that the effectiveness of extracts of Tribulus terrestris in inhibiting ACE activity. ${ }^{18}$ However other mechanisms including a vasodilator effect mediating via a direct effect on the arterial smooth muscle or interfering with other neuroeffective mechanism such as adrenergic system could not be ruled out. ${ }^{19}$ Some scientific studies are reported that the saponins contribute to vasorelaxant effect. ${ }^{20}$ In this study, hypertension was induced by administering $18 \% \mathrm{NaCl}$ to normal rats. It is worth noticing that they also urinated consequently. This diuretic behaviour accounts for an obvious homoeostatic need of their organism frequently associated with increase in oxidative stress and hardening of blood vessels. ${ }^{13,21}$ High salt intake induced increase of plasma SGOT.22 Concomitant administration of $\mathrm{NaCl} 18 \%$ with extract (200 and $400 \mathrm{mg} / \mathrm{kg} /$ day) permitted to reduce less significantly the increase of SGOT and SGPT in hypertensive rats. This result suggests that plant extract might partially protect various tissues, including hepatic tissues, from high salt-induced injuries. ${ }^{21-23}$ As Lantana camara extract prevented that hypercreatinemia, it might prevent any eventual disruption of glomerular filtration. Electrolyte imbalance and alteration in reninangiotensin system plays a key role in the pathogenesis of hypertension. ${ }^{24}$ Numerous epidemiological and intervention studies have demonstrated a positive correlation between sodium intake and elevated blood pressure. ${ }^{21}$ Dietary intake of $\mathrm{K}, \mathrm{Ca}$ and $\mathrm{Mg}$ has been reported to lower blood pressure. Kidney plays a central role in the regulation of the balance of body salt and water, and disordered regulation of renal functions is responsible for the altered balance of hypertension. ${ }^{25}$ Dietary supplementation of $\mathrm{KCl}$ significantly increased GFR in hypertensive rats. The increase in GFR in hypertensive rats treated with potassium may relate to the increase in $\mathrm{NO}$ production. ${ }^{24} E E L C 400 \mathrm{mg} / \mathrm{kg}$ significantly increased the potassium levels on salt induced hypertensive rats. This result suggest that the plant extract might have the effect on potassium levels. In the salt hypertensive rats, the kidney exhibited pathological abnormalities such as cortical degeneration, tubular degeneration, hydrophilic swelling and necrotic changes were observed. In the control, standard and plant extract treated rats, the kidney exhibited a normal architecture. These results suggests that the plant extract might represent support for the antihypertensive activity. EELC having high amount of alkaloids, glycosides, polypeptides, saponins and terpinoids. so this plant having the anti hypertensive property. ${ }^{26}$

\section{CONCLUSION}

The Ethanolic extract of Lantana camara leaves shown hypotensive properties in the anaesthetized chick, which might be involved in smooth muscle relaxation. The present study suggests that treatment of salt hypertensive rats with ethanolic extract of Lantana camara leaves protects against renal and vascular injuries, possibly through the antioxidant activity and maintaining the normal ionic composition. It was concluded that ethanolic extract of Lantana camara leaves reduce work load of heart, and maintain ionic levels by negative chronotropic effect.

These results suggests that the plant extract support for the antihypertensive activity. However, long-term, randomized controlled trials are needed to evaluate the antihypertensive activity.

\section{ACKNOWLEDGEMENT}

We are thanks to management of shri Vishnu college of Pharmacy for providing facilities to conduct this study

\section{CONFLICTS OF INTEREST}

We declare that we have no conflict of interest.

\section{REFERENCES}

1. Scott Gilbert MD. Pathophysiology of Hypertension. Tufts University School of Medicine 2014; 10(6): 364-76. ocw. tufts. edu/data/33/498002

2. Pour BM, Latha LY, Sasidharan S. Cytotoxicity and oral acute toxicity studies of Lantana camara leaf extract. Molecules 2011; 16(5): 3663-74.

3. Ghosh S, Das Sarma M. Anti-inflammatory and anticancer activity of Lantana camara Linn. Journal of pharmacy and pharmacology 2010; 62(9): 1158-66.

4. Ganjewala D, Sam S, Khan KH. Biochemical compositions and antibacterial activities of Lantana camara plants with yellow, lavender, red and white flowers. Eur Asia J Bio Sci. 2009; 3(10): 69-77.

5. Barreto FS, Sousa EO, Campos AR, Costa JGM, Rodrigues FFG. Antibacterial activity of Lantana camara Linn. African Journal of Biotechnology 2010; 2(1): 42-4.

6. Srivastava $D$, Singh $P$. Antifungal potential of two common weeds against plant pathogenic fungi-Alternariasps. Asian Journal of Experimental Biological Sciences 2011; 2(3): 525-8.

7. Venkatachalam T, Kumar VK, Selvi PK, Maske AO, Anbarasan V, Kumar PS. Antidiabetic activity of Lantana camara Linn fruits in normal and streptozotocin-induced diabetic rats. Journal of Pharmacy Research 2011; 4(5): 1550-2.

8. Gidwani BK, Bhargava S, Rao SP, Majoomdar A, Pawar DP, Alaspure RN. Analgesic, anti-inflammatory and antihemorrhoidal activity of aqueous extract of Lantana Camara Linn. Research Journal of Pharmacy and Technology 2009; 2(2): 378-81.

9. Sagar L, Sehgal R, Ojha S. Evaluation of antimotility effect of Lantana camara L. BMC Complementary and Alternative Medicine 2005; 5(1): 18

10. Nayak BS, Raju SS, Eversley M, Ramsubhag A. Evaluation of wound healing activity. BMC Complementary and Alternative Medicine 2009; 23(2): 241-5.

11. Abdulla MA, Hassandarvish P, Ali HM, Noor SM, Mahmoud FH, Ahmad Bashah NS. Acceleration of Wound Healing Potential by Lantana camara Leaf Extract in Experimental Rats. Research Journal of Medical Sciences 2009; 3(2): 75-9.

12. Kokate CK, Purohit AP, Gokhale SB. Pathway to screen phytochemical nature of natural drugs. Pharmacognosy 2007; 19(1): 607-11.

13. Badyal DK, Lata H, Dadhich AP. Animal models of Hypertension and effect of drugs. Indian Journal of pharmacology 2004; 35(6): 349-62.

14. Lilach OL. Animal models of hypertension: An overview. J Lab Clin Med. 2005; 146(3): 160-73.

15. Protais Marcellin Ohandja Edzah, Germain Sotoing Taïwe, Danielle Claude Bilanda, Esther Ngo Lemba Tom, Pierre Kamtchouing, Theophile Dimo. Antihypertensive activities of the aqueous extract of Kalanchoe pinnata in high salt-loaded rats. Journal of Ethnopharmacology 2014; 153(2): 400-7.

16. Cohuet G, Struijker-Boudier H. Mechanisms of target organ damage caused by hypertension. Pharmacology \& therapeutics 2006; 111(1): 81-98.

17. Tripathi S, Rawat K, Swati D, Himani P. Potential of Lantana camara Linn. Weed against wood destroying fungi 2009; 135(3): 403-11.

18. Somanadhan B, Varughese G, Palpu P, Sreedharan R, Gudiksen L, et al. An ethnopharmacological survey for potential angiotensin converting enzyme inhibitors from Indian medicinal plants. Journal of Ethnopharmacology 1999; 65(2): 103-12.

19. Vadivel K, Thangabalan B, Rafi SK, Manohar Babu S. Cardiovascular effects of aqueous leaf extract of Aristolochiabracteata lam. On isolated perfused frog heart preparation 2013; 4(2): 93-8.

20. Cardoso Limal. Structural relationships and vasorelaxant activity of monoterpenes. DARU Journal of Pharmaceutical Sciences 1997; 20(1): 23

21. Bayorh MA, Ganafa AA, Socci RR, Silvestrov N, Abukhalaf IK. The role of oxidative stress in salt-induced hypertension. American Journal of hypertension 2004; 17(1): 31-6.

22. Bopda MOS, Dimo T, Tonkep SI, Zapfack L, Zeufiet DD, Kamtchouing P. Cardio depression as a possible mechanism of the hypotensive effect in rats. African Journal of Biotechnology 2011; 10(72): 16393-401.

23. Ofem Ofem Effiong, Victor Nna Udo, Essien Nsima Monday. Reduction in Serum Bilirubin Concentration Following Administration of Crude Leaf Extract of Viscum album in High Salt Fed Rats. British Journal of Pharmaceutical Research. 2014; 4(3): 352-361.

24. Hawzheen Karem Othman, Almas, Mahmud MR. Effects of Potassium and Magnesium on Some Hemodynamic and Renal Function Related Parameters in 2k1c Hypertensive Rats. IOSR Journal of Pharmacy 2012; 2(6): 2250-3013

25. Devarajan Bhagya, Lalitha Prema, Thankappan Rajamohan. Tender coconut water maintains the level of electrolytes and renin in fructose-fed hypertensive rats. Int $J$ Biol Med Res. 2010; 1(3): 44-4.

26. Reddy NM. Lantana Camara Linn. Chemical Constituents and Medicinal Properties 2013; 2 (6): 445-8. 


ABOUT AUTHORS
Praveen Kumar Pasala: Presently working as Associate professor in the Dept of Pharmacology, Shri Vishnu college of Pharmacy, Andhra
university, Bhimavaram. He had two Indian patents (Processing), UGC Minor project (Onging) 7 nos. Of international papers.
Dr. Silvia Netala: Presently working as Associate professor in the Dept of Pharmacology, Shri Vishnu college of Pharmacy, Andhra univer-
sity. she had 5 nos. Of international papers.
Dr. Prasad Konduri: Presently working as Professor in the Dept of Pharmacology, Shri Vishnu college of Pharmacy, Andhra university. He
had more than 15 nos. Of international and national papers. Prasad also PCI APTI and member. He finished AICTE (rps) project.
Vijay Kumar Matta and Satish Pandrinki: PG in Pharmacology department.

